\title{
Multi-Strand Narrative Structures: A Filmic Game of Multiple Players
}

\section{Fátima Chinita}

\begin{abstract}
Some films are multi-plot narratives operating as a network of related events played out by a large number of core characters. Since these characters are all protagonists in their own right, this results in a complex form of storytelling that can be used for dramatic purposes as well as for comedy. In both cases, however, there is a sort of play at stake here because the screenwriter is forced to mingle them all in a single film, thus stressing the storytelling over the story told. Enter the director, centre stage. The story on paper, i.e. the script, has to gain another life as characters are portrayed by actors and the game of shooting begins. Here the director, by using certain filmic techniques that reinforce his/her own role as puppet master, adds another layer of narration to the film, thus further stressing the storytelling and its playful, although not necessarily joyful, nature. In the film Happy Endings - written and directed by Don Roos, 2005, USA ${ }^{1}$ - the scrambling and re-scrambling of character's lives in one single multiple and complex plot, via the art of the filmmakers and the craft of the actors invested in their roles, reveals itself to be not only playful but joyful as well. The film is a comedy where the events are doubly enunciated: as actions portrayed by people, and as text written large over the image as the actions evolve. Thus, the director writes himself onscreen as an artist just as is he is literally writing his characters bios and convolutions. What a playful and thoroughly self-conscious storytelling this is, reminiscent of some of Woody Allen's masterpieces.
\end{abstract}

Key Words: Multi-plot, multi-strand narrative structures, complex multiple narrative, storytelling, network, Happy Endings.

$* * * * *$

\section{Choral Films, or the Never Ending Mosaic Agency}

Dan Hassler-Forest, in 'Multiple Narrative Structures in Contemporary Cinema', advocates the concept of 'complex multiple narrative' applied to films with a lot of characters whose existential paths collide. In his opinion, the more the number of intertwined narrative lines in a single film increases, the more the attention of the film viewers is transferred from the story to the plot. In other words, the spectator begins to pay attention to the transitions, parallelisms and differences that exist between the several stories and their micro universes instead of worrying about what will happen next in each single one of them. The film, thus, obliterates the traditional logic of cause and effect, making the course of 
events very unpredictable. It seems to me that the die is cast for a game between filmmaking storytellers and decoding film viewers.

In fact, these narratives are not organized around actions; they are structured around characters, which may vary considerably in number from one film to another. Magnolia ${ }^{2}$ is structured around 11 main characters, while in Bobby ${ }^{3}$ the number increases to an impressive 22. The human beings and their personal dramas are the story that needs to be recounted and that merits attention from the spectators.

These plots, which fall under the category of what Robert McKee, in Story, calls 'multi plots', are clearly choral in that it makes no sense whatsoever to speak of protagonists since that role is shared by (almost) all of the diegetic people in the film. According to McKee, the multi plot films do not develop a central plot. They are actually formed by a set of stories the size of subplots (secondary narrative lines) and, ordinarily, follow the principle of variation and contradiction: the several plots intersect one another, being unified by a leitmotif or idea. ${ }^{4}$ McKee's explanation, which helps to understand the workings of such collectively acted films (that I designate as 'choral films'), must be approached with some care. In fact, McKee is not after the principles of narratology; he simply wants to mentally format the films so that they can conform to writing patters, which implies taking into consideration the classical 'three-act structure' made famous by Syd Field, in his book Screenplay, and, consequently, falling into the temptation of looking for 'plot points'.

It seems to me that these writing restraints do not adequately serve the approach of these mosaic type narratives, which are so fragmentary in nature and playfully stimulating.

Inevitably, with so many narrative lines progressing simultaneously the spectator is cognitively challenged, since a lot more attention is required to follow these films. Dan Hassler-Forest mentions the necessary existence of spatial and temporal parameters to help the viewer gather his/her bearings and to determine the simultaneity of the ongoing events. According to this scholar, these occurrences usually take place during a clearly signaled time lapse and in a particular space. At the end of the film there is a narrative closure, although not necessarily cathartic, which reunites all the characters in one place and/or affects them all at the same time. Throughout the film, starting with the opening credits and the presentation of characters, the movie advances by alternating between the several diegetic people. The crosscutting establishes from early on the physical proximity of all the protagonists and the preferential method of narration, which fluctuates between several narrative lines. The change of story invariably happens in these films through a cut, instead of a dissolve or a fade, because the films do not consider this commutation of scenes and/or sequences as a division resulting from narrative objectives achieved. Accordingly, the degree of character motivation varies quite a lot from film to film. In some cases the diegetic figures have strong psychological 
justifications for their actions, which are progressively made clear throughout the film (e.g. Magnolia). In other instances the human motivations are simply conveyed in sketches of stock characters (e.g. Me and You and Everyone We Know ${ }^{5}$ ). In any case, there is always less depth involved than in the single or double protagonist films.

David Bordwell, in 'Mutual Friends and Chronologies of Chance', also addresses the same subject but uses a different nomenclature for it: 'network narratives' or 'the crisscross format'. He considers that this type of fiction is modeled according to the theory of the six degrees of separation, ${ }^{6}$ which is both a recognized scientific fact and part of a folk collective imaginary. According to the chaos theory, which is a more serious version of it, life is a string of events that tend to trigger other events in a snowball-like motion known as 'the butterfly effect'. ${ }^{7}$ Despite the great quantity of protagonists, all placed at the same level of importance in the film and having pretty much the same screen time, the connections between them are weak or even contingent because the principal aspects of the formula are chance and parallelism. In Bordwell's opinion, the crosscutting and chance occurrences only reinforce what he perceives to be an overall narrative fragility and not, as I advocate, a playful and stimulating activity of film viewing. Indeed, instead of the usual causality, the film brings out a pattern of relationships which is almost geometrical and that is only discernible if we take a step back and look at the overall film as a whole.

Rather than the haphazard nature of the convergence of characters, at those moments of the plot where their destinies meet or intersect, what I find relevant is the fact that the films can even defer this/these occurrence(s) so as to generate more curiosity in the spectator. Bordwell himself acknowledges that the recombination of characters is a resource available to the director, since the points of convergence, whatever their magnitude or relevance, can become more important than the separate lines of action. Besides the editing, he mentions two other linking strategies: (a) some means of communication (e.g. characters talk on the phone or see/hear the same media program); (b) some action commonplaces, of which the more commonly used is the car accident, because it is a fortuitous act that can make several characters collide, in the most literal sense with grave consequences.

The editing, however, is absolutely crucial, and for more reasons than those expounded by Hassler-Forest. In fact, it serves well the aim of revealing, anticipating or hiding information from the viewer. The crosscutting is generally used with the spectator in mind because it connects, from the start, in the viewer's head, characters whose paths may physically intersect only a long way further down the narrative. Actually, in all honesty, Bordwell mentions that this type of narrative develops in two simultaneous blocks: forward (the progress of the plot) and backwards (the transmission of data about the characters' back story). Also 
according to him, the editing can, furthermore, serve to contradistinguish different characters or, conversely, to reinforce their common aspects.

Despite the reductionist and formulaic logic that guides him Bordwell recognizes the enunciative importance of the mosaic narratives of choral dimension: 'Like a mystery film, the network narrative frankly exposes the act of narration, inviting the viewer to build inferences out of teases, hints, and gaps'. ${ }^{8}$ However, he considers these films to have a realist penchant which is totally contrary to my own opinion on the subject. The proverbial 'slice of life' and the likewise commonplace of the 'human gallery' are of no interest to me, unless we consider the additional reasons of the screenwriter/director for wanting to make such films. Although he talks about the film's architecture, Bordwell is incapable of realizing that this is an end in itself.

In Stavros Halvatzis categorization, which constitutes a more apt approach of the subject, these films are called 'multi-strand narrative structures', which is a good merging of all the nuances several other nomenclatures contain. For this scholar

The term multistrand, then, preserves the idea of a single, intricate, complex, but purposeful pattern of links, which, despite ostensible appearances of looseness is, after all, the result of meticulous and purposeful planning on the part of the writer. ${ }^{9}$

According to Halvatzis, the multi-agency narratives contain more than one chain of events (as long as they are not mutually exclusive) and, therefore, several protagonists and antagonists. The various heroes are protagonists in their stories (which have a gallery of secondary characters) but may also appear as secondary characters themselves in the narrative lines of others. This fact is not enough to make one think of subplots as far as the whole film is concerned, because these characters, having more overall importance and occupying more screen time, cannot be confused with the typical secondary characters. Their development is substantial and parts of the film are even narrated from their point of view. In face of the diegetic multiplicity of protagonists, the multi-agency films require a unifying substance that Halvatzis calls 'spine', which is a core of either a thematic, philosophical or moral nature, and which is conveyed in the plot through the technical and stylistic resources.

Halvatzis sees the multi-agency narratives as being subdivided in two groups, of which only the second (the 'complex' multi-strand variety) has forcibly more than four main agents. To sum his theory: the complex multi-agency narrative has a diegesis centered on the characters; the crosscutting transmits moral and thematic imperatives, as well as an abundant use of symbolism; the plot is highly redundant; the characters are very well defined to start with (the films have a long set-up); the behavioural traits of each agent are reduced to a minimum and are related with a 
central event in their lives; the coincidences are responsible for open endings in the third act.

To conclude, let me say that these choral/mosaic narratives are all reflexive and that some of them are even meta-narrative, because they issue a discourse on fictional cinema itself. However, for that to happen, the films need not only to articulate a wide group of people with parallel stories, but the human figures need to gravitate in the orbit of show business, so as to depict cinema, either directly or metonymically.

\section{Happy Endings as an Enunciate Intertwining of Middles}

Don Roos' Happy Endings - 2005, USA - is a good case study in that it corresponds to a multi-agency film, therefore evincing choral articulations that have no other formal objective but to demonstrate, in filmic terms, the nature and versatility of the articulations undertaken. So much so that, unlike most of the films that follow this sort of structure, this opus is a comedy, proving my point that such a narrative device can, and should, be used as a sort of play, either to demonstrate the artistry of the filmmakers behind the storytelling or to claim the storytelling as play (in this case of a ludic nature). In this particular film both things happen: the entertainment value of the interlacing of narrative lines is not separated from a discourse on filmic narrative itself (reinforced by the fact that several of the characters work in the Los Angeles artistic community).

So meta-narrative is the articulation between characters that the film corroborates it through the use of inter-titles, direct emanation of the mega enunciator (i.e. the director and/or screenwriter). Thus, the authorial discourse is made irrefutable. The film is structured around ten main characters whose lives intersect one another throughout, but without the benefit of a collective climax.

Mamie (Lisa Kudrow) had, at 17, a son by her half-brother Charley (Steve Coogan) and a long time afterwards is confronted with that fact by a young man, Nicky (Jesse Bradford), who wishes to direct a documentary project about the horrors of putting a child up for adoption. Nicky's sensationalist goal is directed towards making him obtain a grant from the American Film Institute in New York, which is why he doesn't hesitate to blackmail Mamie into participating in his project and endowing him with a winning film. His exchange currency is effective: he knows the whereabouts of Mamie's son, now a teenager of 17 (and he intends to explore the fact in a painful recorded reunion between mother and repudiated son). Mamie gives in to Nicky's wishes, but manages to make him abandon his initial project in favor of another one centered on a Mexican sexual worker, Javier (Bobby Cannavale), an erotic masseur who befriends Mamie.

Charley, Mamie's half-brother, is now gay and has lived for five years with Gil (David Sutcliffe). The latter has agreed to father a child of a lesbian couple of friends, Pam (Laura Dern) and Diane (Sarah Clarke), but the failure of the endeavour has made them turn to a bank sperm instead. Charley is convinced that 
the child is, in effect, daughter of Gil and enters a crusade to prove that the couple of women have stolen Gil's sperm, which proves to be untrue and, ultimately, causes the breakup of the two pairs of friends and the couple Charley/Gil itself. Charley runs the restaurant that his late parents (and Mamie's) have left him.

Charley's restaurant employs the young Otis (Jason Ritter), who is the drummer in a garage band that also performs at the restaurant, which doubles as karaoke bar. When the boy realizes that a sexy and provocative female patron, Jude (Maggie Gyllenhaal), has a knack for singing, he invites her to become the band's vocalist. Jude accepts, and when she realizes that Otis is a closet gay (in fact in love with his boss, Charley), she seduces him and poses as his girlfriend in order to deceive the boy's father, Frank (Tom Arnold). Invited to come and live at the pool house of the luxurious mansion where Otis and Frank reside, Jude doesn't hesitate to seduce the father as well. Meanwhile, she uses Otis real sexual orientation to blackmail him into not disclosing her real intention, which is to be kept by a wealthy man.

Although the fate of the most part of the characters intersects, one can discern three more individualized nuclei of action, as the above synopsis proves. The character's fate also intersects, albeit more sporadically, between nuclei. In fact, after having been repudiated by Frank, Jude visits the clinic where Mamie works as a medical professional; after having seen his son, who doesn't recognize her, Mamie runs and is hit by Pam's car; at the end, Mamie marries Frank, enabling her and Charley to see their son and keep up with him for some time of his life.

However, what distinguishes Happy Endings from other mosaic type narratives is the permanent knowledge that the mega enunciator reveals about the characters, not hesitating to reveal future facts in relation to the particular story moment that the narrative is at. In other words, this film is a draw-well of back story and 'future story,' so to speak, to which the storyteller or mega-enunciator resorts in order to spice up the events and to mock them. Therefore, the 'story' doesn't have an irreducible and constant temporality, being, instead, a sort of a temporal continuum, of which the mega-enunciator Roos draws elements according to his/her wishes or needs. The storyteller can fast forward to reveal, by the use of inter-titles, aspects not directly connected to the present actions, or can rewind, going back to earlier facts either depicted in the film or totally absent from the images and sounds.

These inter-titles are usually accompanied by a rectangle of screen image, which is a sort of pictorial tile where we can see the action that the written text illustrates or comments upon. Their large number only serves to fragment the opus even further, and, visually, enunciates the very narrative subdivision that characterizes the film. The inter-titles themselves behave as a Greek chorus, but of a humorous nature, highlighting the choral nature of the film as a whole. They may serve to introduce the story, preparing the viewer for what he/she is about to see ('She's not dead. No one dies in this movie, not on-screen. It's a comedy sort of.); 
they may present characters and describe them ('Charley Peppitone, 16, her new stepbrother. English'); they may weave commentaries about the characters or the action ('Nicky never lies. He is not her son, if that's what you're thinking. But he does know him.'); they may reveal certain diegetic thoughts ('Mamie wonders why she cares about Nick's movie. And why, when he frightens her, she cares even more.'); and, above all, they may supply the viewer with temporal clues about the past (What happens next happened twenty years ago) or the future, as a sort of narrative oracle:

He's a virgin for ten more minutes. [...]

He will have sex with just two more [women] past Jude. In the last week of his life a nurse will remind him of Jude and she will know his smiles are for her; but in 20 years he's happier than anyone else. But that's another story. ${ }^{10}$

Underneath a form of enunciation, that of the filmic direct speech, another form of discourse inscribes itself, that of the authorial commentary.

The inter-titles don't even hesitate to tie up the loose endings: 'Six months later there are a lot of endings. The reference to the endings (generally happy) is a hint to the film title, but it is also related to two other aspects: (a) the documentary film that Nick directs (which is also entitled Happy Endings, as we can perceive by a quick glance at the intra-diegetic main credits); (b) the climax of the erotic massages provided by Javier, which can induce orgasms in his female clients. Together, these three factors emphasize the enunciation as a theme. The first draws on the articulation of the characters and the work of the screenwriter; the second indicates the potentially meta-cinematic nature of this particular meta-narrative; the third reveals the genre in which the film tries to inscribe itself and rewrite: the comedy of manners, itself made up of an aggregate of people interacting amongst themselves.

\section{Notes}

${ }^{1}$ Happy Endings, dir. Don Roos. Los Angeles: Sony Pictures Home Entertainment, 2006, DVD.

2 Magnolia, dir. Paul Thomas Anderson. Boston: Emerson Independent Video, 1999, DVD.

${ }^{3}$ Bobby, dir. Emilio Estevez. London: Momentum Pictures, 2007, DVD.

${ }^{4}$ This is what happens, for instance, in the Oscar awarded Best Film Crash - Paul Haggis, 2004, USA/GER - which, from the onset, articulates all the narratives around a message of racial tolerance, albeit it depicts the consequences of a reality diametrically opposed to this predication. 
${ }^{5}$ Me and You and Everyone We Know, dir. Miranda July. Paris: StudioCanal, 2006, DVD.

${ }^{6}$ According to this theory, everybody is only six people away from meeting everybody else, whoever that person may be and no matter where she is. The idea was employed for the first time in a 1929 short story by the Hungarian writer Frigyes Karinthy, which, in turn, originated the $\mathrm{PhD}$ thesis of Michael Gurevitch about the operation of social networks, edited in 1961, which ended up encouraging similar researches in the field of mathematics.

${ }^{7}$ The butterfly effect is part of the chaos theory, which deals with the interaction of certain elements in a practically random fashion. It was first defended in 1963 by the meteorologist Edward Lorenz as a way to explain climactic phenomena that occurred in the planet. In this perspective, the simple beating of the wings of a butterfly in one place can cause a natural catastrophe of epic dimensions in another part of the world. The films The Butterfly Effect (dir. Eric Bress, J. Mackye Gruber. London: Icon Home Entertainment, 2007, DVD) and Le Battement d'ailles du pappillon (dir. Laurent Firode. Paris: Éditions Montparnasse, n/d, DVD), both directly based on this premise, cannot, however, in my opinion, be considered mosaic type narratives. The former is a forking path narrative structured around the point of view of different characters; the latter has only two protagonists. The film The Air I Breathe (dir. Jieho Lee. Los Angeles: Twentieth Century Fox, 2008, DVD) manages to better convey the random interaction of narrative elements within a story that interlinks four protagonists. Actually, the promotional poster of the film shows a silhouetted hand that holds a gun on top of which a colored butterfly can be seen resting.

${ }^{8}$ David Bordwell. 'Mutual Friends and Chronologies of Chance', Poetics of Cinema (New York and London: Routledge, 2008): 200.

9 Stavros Halvatzis. 'Multfiform and Multistrand Narrative Structures in Hollywood Cinema', (PhD Dissertation, University of Southern Queensland, 2011), 152. Halvatzis dismisses the other terms in use, one by one. It is his contention that the much used concept of 'narrative ensemble' always ends up by recalling the films permeated with stars (known as 'ensemble cast') and which usually have linear plots; the term 'network narratives' can be used indiscriminately in all types of films that do not have a central cast; the label of 'multiple narratives' suggests a much larger division between the several narrative lines than what really happens; and the expression 'multi-protagonist films', although it corresponds better to the attributes of the category, doesn' $t$ ' have a traditional protagonist in the sense of hero.

${ }^{10}$ All the quotations from the film are taken from the DVD version (Sony Pictures Home Entertainment, 2006). Occasionally this technique is also used without intertitles, but such use is rare. 


\section{Bibliography}

Bobby. Directed by Emilio Estevez. London: Momentum Pictures, 2007, DVD.

Bordwell, David. 'Mutual Friends and Chronologies of Chance'. Poetics of Cinema, 189-250. New York and London: Routledge, 2008.

Crash. Directed by Paul Haggis. Los Angeles: Twentieth Century Fox, 2005, DVD.

Field, Syd. Screenplay: The Foundations of Screenwriting. New York: Dell, 1979.

Halvatzis, Stavros. 'Multiform and Multistrand Narrative Structures in Hollywood Cinema'. PhD. Dissertation, University of Southern Queensland, 2011. Viewed on 14 February 2013. http://eprints.usq.edu/au/20763/2/Halvatzis_2011_whole.pdf.

Happy Endings. Directed by Don Roos. Los Angeles: Sony Pictures Home Entertainment, n/d, DVD.

Hassler-Forest, Dan. 'Multiple Narrative Structures in Contemporary Cinema. MA dissertation, University of Amsterdam, 1999. Viewed on 1 February 2012. http://www.euronet.nl/users/mcbeijer/dan/mns/complex.html.

Le Battement d'ailles du pappillon. Directed by Laurent Firode. Paris: Éditions Montparnasse, $\mathrm{n} / \mathrm{d}$, DVD.

Magnolia. Directed by Paul Thomas Anderson. Boston: Emerson Independent Video, 1999, DVD.

McKee, Robert. Story: Substance: Structure, Style and the Principles of Screenwriting. London: Methuen, 1998.

Me and You and Everyone We Know. Directed by Miranda July. Paris: StudioCanal, 2006, DVD.

Murphy, J.J. Me, and You and Memento and Fargo: How Independent Screenplays Work. New York and London: Continuum Books, 2007.

The Air I Breathe. Directed by Jieho Lee. Los Angeles: Twentieth Century Fox, 2008, DVD. 
The Buttefly Effect. Directed by Eric Bress, J. Mackye Gruber. London: Icon Home Entertainment, 2007, DVD.

Fátima Chinita is a Professor of Cinema at the Lisbon Higher Polytechnic, Drama and Film School, in Portugal. She has a PhD. in Art Studies (Cinema) and has written a book on David Lynch [in Portuguese]. She writes on meta-cinema, metanarrative and spectatorship. 